\title{
A note on value investing in the UAE stock market
}

\author{
Mateusz Mikutowskia*, George D. Kambouris ${ }^{b,}$, Adam Zaremba ${ }^{a, b}$ \\ a Department of Investment and Capital Markets, Faculty of Management, Poznań University of Economics and Business, \\ Poland, mateusz.mikutowski@ue.poznan.pl, adam.zaremba@ue.poznan.pl. \\ ${ }^{b}$ Dubai Business School, University of Dubai, Dubai, Academic City, P.O. Box 14143, Dubai, United Arab Emirates, \\ gkambouris@ud.ac.ae, adam.zaremba@ud.ac.ae. \\ ${ }^{*}$ Corresponding author.
}

Received: 17 June 2019; revised: 25 June 2019; accepted: 25 June 2019; published: 26 June 2019.

\begin{abstract}
Value investing is one of the most popular stock-picking strategies employed in financial markets. We investigate its effectiveness in the United Arab Emirates. We examine the performance of 124 firms in the period from January 2004 to March 2019. We analyze portfolios from one-way sorts on several well-known valuation ratios: earnings-to-price, book-to-market, EBITDA-to-EV, and dividend yield. Our results demonstrate a powerful value effect in the UAE stock markets. The long-short strategies based on valuation ratios display high raw and risk-adjusted returns. Our results are robust to many considerations.
\end{abstract}

Keywords: stock market, equity anomalies, value investing, asset pricing, return predictability, value effect, United Arab Emirates, emerging markets, UAE.

JEL codes: G11, G12, G14

\section{INTRODUCTION}

Value investing is one of the most popular investment strategies with seminal studies published almost a century ago (Graham 2006; 2008). Value investing assumes buying stocks, at a price below their intrinsic value. One of the main ways of implementing the strategy is to use valuation multiples, which fall into one of two categories: equity multiples (metrics that compare various accounting items to the market value of company's equity, e.g. E/P or B/M) or enterprise values (metrics that compare various accounting items to the sum of market value of a company's equity and its debt e.g. EBITDA/EV). Finally, another, but not that popular proxy of value, is the dividend yield.

The value investing strategy has been investigated in numerous countries: in the USA e.g. by Nicholson (1960), Basu (1975, 1977, 1983), Fama and French (1992); in Bangladesh or Lebanon by De Groot et al. (2012); in France, Germany, Netherlands, and the United Kingdom by Brouwer et al. (1996); in Peru by Da Silva, (2001), in Pakistan by Soomro and Haroon (2015), in Japan by Chan et al. (1991), or in Poland by Zaremba and Szyszka (2016) and Zaremba, Czapkiewicz, Szczygielski, and Kaganov (2019).

The aim of this study is to examine the effectiveness of the value investing approach in the United Arab Emirates stock market. Since its launch in 2000, the UAE stock market has hardened its connection with global markets and year by year is getting more attention from global investors (Maghyereh \& Awartani, 2012). The goal of this article is to verify the effectiveness of the value investing strategy in the United Arab Emirates equity market. This study contributes to the literature on asset pricing and equity anomalies in the UAE equity market and in the Middle East (Alshebli 2019; Al-Kahazali, 2008; Al-Hajieh et al., 2011; Al-Tamimi et al., 2011; Bedier \& AbdelAzim, 2019; Chiang \& Zheng, 2010; Kouzez \& Lecointre-Erickson, 2019; Medhioub \& Chaffai, 2018; Moustafa, 2004;).

We demonstrate a clear value effect on the UAE stock market. The long-short portfolios formed on different valuation measures - e.g., earnings-to-price, book-to-market, and EBITDA-to-EV - produce robust mean raw and risk-adjusted returns. The value investing strategy performs very well when implemented using equalweighted portfolios in a diversified and large sample of companies. For value-weighted portfolios and large companies, the phenomenon is markedly weaker.

http://dx.doi.org/10.30585/jrems.v1i2.339

(C) 2018 the Authors. Production and hosting by Avicenna FZ LLC. on behalf of Dubai Business School, University of Dubai, UAE. This is an open-access article under the CC BY-NC license (https://creativecommons.org/licenses/by-nc/4.0/). 
The remainder of the article proceeds as follows. Section 2 describes our dataset. Section 3 outline the methods of our study. Section 4 examines the value investment strategy in the UAE stock market with the use of portfolios sorts. Finally, Section 5 concludes the study.

\section{DATA}

In our research, we use all the companies listed in the UAE's (two markets: the Dubai Financial Market and the Abu Dhabi Stock Exchange. We analyze primary securities only and use monthly returns during in the period from January 2004 through to March 2019 (all data is available in Bloomberg). In addition divide the sample into two subsamples: "all listed companies" and "large companies" (market capitalization more than AED 10 bln). The dataset consists of 124 companies in total. The number of companies in the dataset varies in time from 33 to 109. Figure 1 shows the number of companies in the sample over the analysis period. :

Figure 1. Number of firms in the sample

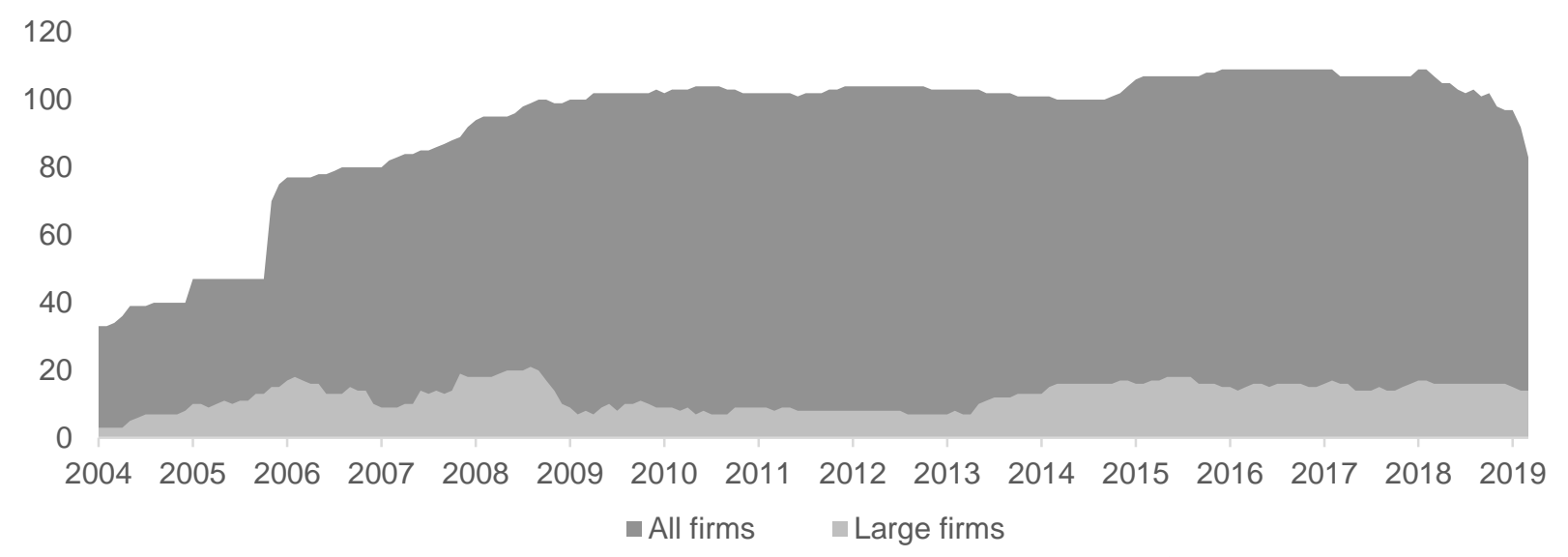

Note: The Figure presents the number of companies in the analyzed sample. Source: Bloomberg.

The summarized value of companies in the dataset varies from AED $65.17 \mathrm{bln}$ to AED $688.81 \mathrm{bln}$. The valuation of companies in the UAE stock markets in stagnation after a vast decline of the market value in 2008 has grown rapidly in the period between 2013 - 2015. In the last period of our research, (March 2019,) the UAE stock markets were evaluated at AED 758.89 bln and $82.6 \%$ of their its value was created by 14 out of 83 listed companies. In earlier periods, large companies had participated at a minimum of $48.2 \%$ and a maximum of $88.9 \%$ of the entire market capitalization. Figure 2 shows the value of companies in the sample:

Figure 2. Value of firms in the sample (in AED bln)

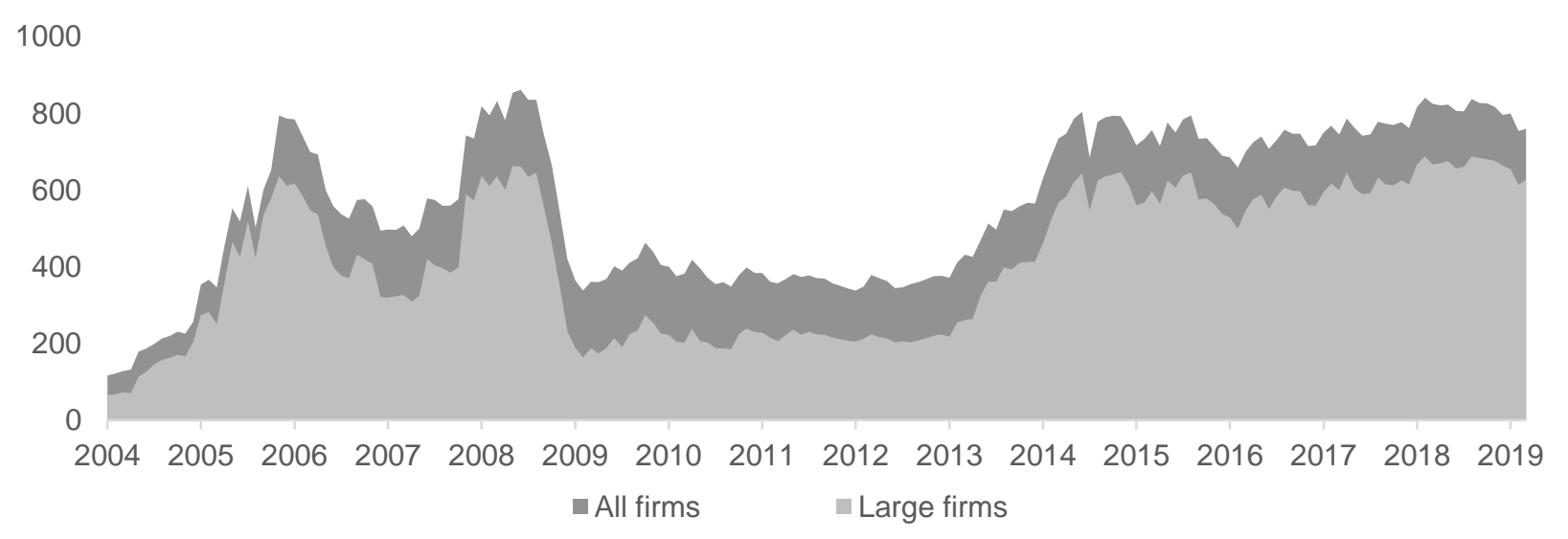

Note: The Figure presents the value of companies in the analyzed sample. Source: Bloomberg.

\section{METHODS}

We perform all the tests in the full sample of all the companies and within a subsample of thee large firms only. We use four different return predictive variables representing firm value: a) earnings-to-price ratio (Graham \& Dodd, 1940; Basu, 1975; 1977; 1983), i.e., the 12-month earnings over the current market price; b) book-tomarket ratio (e.g. Rosenberg, Reid, and Lanstein in 1985; Chan et al. 1991; Fama \& French, 1998; Asness et al. 2013); c) dividend yield (e.g. Fama \& French, 1988; Goetzmann \& Jorion, 1995; Campbell \& Yogo, 2006; 
Zaremba \& Konieczka, 2015); and d) EBITDA-to-EV ratio (Loughran \& Wellman, 2011; Gray \& Vogel, 2012) in the study we base on 12-month EBITDA and current EV.

Each month, we rank all the stocks in the sample on each of the predictive variables mentioned above and form equal- and value-weighted tercile portfolios. We also construct the long-short portfolios that are long in the tercile of stocks with the highest value indicator and simultaneously short the tercile of the stocks with the lowest value indicators.

For each portfolio, we calculate Sharpe ratios (annualized) (Sharpe, 1966) and CAPM alphas (Sharpe, 1964). The $t$-statistics are computed using the bootstrap method for mean returns and Newey-West (1987) for alphas.

All stocks prices are in UAE dirhams (AED). We use the 3-month US T-bill rate from the Kenneth French website for a risk-free rate. (the currency in UAE is pegged to the US dollar). All the accounting values are lagged by 6 months to avoid look-ahead bias.

\section{ANALYSIS AND RESULTS}

\subsection{Portfolio sorts}

\subsubsection{Strategies in all companies}

The table demonstrates the performance of portfolios from one-way sorts on different valuation measures. In the case of equal-weighted portfolios, almost all of the strategies produce significant and economically large profits and alphas. The remarkable winner of the horserace is the single-sorts on the B/M ratio, with the mean monthly return (alpha) on the long-short portfolio amounting to $1.66 \%(1.66 \%)$.

Table 1. Strategies in All Companies

\begin{tabular}{|c|c|c|c|c|c|c|c|c|}
\hline & \multicolumn{4}{|c|}{ Equal-weighted portfolios } & \multicolumn{4}{|c|}{ Value-weighted portfolios } \\
\hline & Low & Medium & High & High-Low & Low & Medium & High & High-Low \\
\hline \multicolumn{9}{|c|}{ Panel A: Portfolios from sorts on the earnings-to-price ratio } \\
\hline \multirow[t]{2}{*}{$\mathrm{R}$} & 0.62 & $1.46^{\star \star \star}$ & $1.99^{\star \star *}$ & $1.37^{\star \star \star}$ & 0.70 & $1.18^{* *}$ & $1.38^{* *}$ & 0.67 \\
\hline & $(1.17)$ & $(2.73)$ & (3.90) & (3.55) & $(1.12)$ & $(2.21)$ & (2.23) & $(1.38)$ \\
\hline Vol & 7.17 & 7.02 & 7.25 & 4.75 & 9.38 & 7.18 & 9.33 & 7.08 \\
\hline SR & 0.30 & 0.72 & 0.95 & 1.00 & 0.26 & 0.57 & 0.51 & 0.33 \\
\hline \multirow[t]{3}{*}{$\alpha$} & -0.15 & $0.73^{* \star *}$ & $1.21^{* \star *}$ & $1.36^{* * *}$ & -0.31 & 0.39 & 0.33 & 0.64 \\
\hline & $(-0.47)$ & (2.83) & $(4.22)$ & (3.64) & $(-0.77)$ & $(1.58)$ & (1.33) & (1.38) \\
\hline & \multicolumn{8}{|c|}{ Panel B: Portfolios from sorts on the book-to-market ratio } \\
\hline \multirow[t]{2}{*}{$\mathrm{R}$} & 0.22 & $0.94^{*}$ & $1.88^{\star \star \star}$ & $1.66^{\star \star \star}$ & 0.81 & $1.17^{*}$ & $1.57^{\star \star}$ & 0.75 \\
\hline & $(0.57)$ & (1.84) & (3.57) & (3.73) & (1.51) & $(1.86)$ & (2.43) & (1.46) \\
\hline Vol & 6.37 & 6.44 & 7.11 & 5.46 & 7.69 & 8.62 & 8.55 & 6.64 \\
\hline SR & 0.12 & 0.51 & 0.92 & 1.05 & 0.36 & 0.47 & 0.64 & 0.39 \\
\hline \multirow[t]{3}{*}{$\alpha$} & -0.49 & 0.25 & $1.18^{\star \star \star}$ & $1.66^{\star \star \star}$ & -0.09 & 0.22 & $0.70^{* *}$ & 0.79 \\
\hline & $(-1.54)$ & (1.49) & (3.33) & (3.57) & $(-0.43)$ & (0.88) & (2.06) & (1.60) \\
\hline & \multicolumn{8}{|c|}{ Panel C: Portfolios from sorts on dividend yield } \\
\hline \multirow[t]{2}{*}{$\mathrm{R}$} & $1.15^{\star \star}$ & $0.79^{\star}$ & $1.42^{\star \star \star}$ & 0.26 & $1.30^{*}$ & 0.85 & $1.19^{* \star}$ & -0.11 \\
\hline & $(2.13)$ & (1.83) & (3.60) & $(0.79)$ & $(1.85)$ & $(1.63)$ & (2.13) & $(-0.31)$ \\
\hline Vol & 7.41 & 5.84 & 5.67 & 4.47 & 10.18 & 7.66 & 8.27 & 8.06 \\
\hline SR & 0.54 & 0.47 & 0.87 & 0.20 & 0.44 & 0.38 & 0.50 & -0.05 \\
\hline \multirow[t]{3}{*}{$\alpha$} & 0.32 & 0.11 & $0.76^{* *}$ & 0.45 & 0.18 & -0.11 & 0.18 & 0.00 \\
\hline & $(0.92)$ & $(0.54)$ & (2.32) & $(1.15)$ & $(0.53)$ & $(-0.83)$ & $(0.97)$ & $(0.00)$ \\
\hline & \multicolumn{8}{|c|}{ Panel D: Portfolios from sorts on EBITDA-to-EV ratio } \\
\hline \multirow[t]{2}{*}{$\mathrm{R}$} & 0.30 & $1.59^{\star \star \star}$ & $1.78^{\star \star \star}$ & $1.47^{\star \star \star}$ & 0.72 & $1.34^{* *}$ & $1.58^{* \star}$ & 0.86 \\
\hline & $(0.62)$ & (2.68) & $(2.94)$ & (4.08) & $(0.98)$ & $(2.08)$ & (2.04) & (1.23) \\
\hline Vol & 7.36 & 8.23 & 7.69 & 4.79 & 9.95 & 9.24 & 9.93 & 9.37 \\
\hline SR & 0.14 & 0.67 & 0.80 & 1.06 & 0.25 & 0.50 & 0.55 & 0.32 \\
\hline \multirow[t]{2}{*}{$\alpha$} & $-0.53^{* *}$ & $0.73^{* *}$ & $0.98^{* * *}$ & $1.51^{* * *}$ & -0.33 & 0.31 & $0.62^{*}$ & $0.95^{\star \star \star}$ \\
\hline & $(-2.18)$ & (2.03) & (3.61) & (6.21) & $(-1.19)$ & (1.09) & (1.89) & (2.61) \\
\hline
\end{tabular}

Note. The table discloses the performance of equal- and value-weighted tercile portfolios from sorts on the earnings-toprice ratio (Panel $A$ ), book-to-market ratio (Panel B), dividend yield (Panel C), EBITDA-to-EV ratio (Panel D). High (Low) represents the portfolio of stocks with the $1 / 3$ highest (lowest) values of predictive variables representing firm value, Medium 
represents the portfolio of stocks with predictors values between the group of $1 / 3$ highest and $1 / 3$ lowest. High-Low is the zero-investment portfolio going long (short) the High (Low) tercile. R is the mean monthly return, Vol represents the standard deviation, $S R$ is the annualized Sharpe ratio and the symbol $\alpha$ represents the average monthly abnormal return intercepted from the CAPM model. Average returns, volatilities, and alphas are expressed in percentages terms. The numbers in parentheses are bootstrap and Newey-West (1987) adjusted $t$-statistics for the means of returns and alphas, respectively. The asterisks *, ${ }^{* *}$, and ${ }^{* * *}$ indicate statistical significance at the $10 \%, 5 \%$, and $1 \%$ levels, respectively.

Interestingly, the performance of the value-weighted portfolios is visibly less impressive, suggesting that the value effect may be concentrated mostly in small firms. To dig this effect further, we continue with the analysis of the subsample of large companies only.

\subsubsection{Strategies in large firms}

Next, we perform portfolio sorts within the subsample of large firms to make our analysis more realistic in market view. The strategies in large firms appear to be less effective than in all companies sample. Again, the most impressive strategy is the one based on $\mathrm{B} / \mathrm{M}$ - in this case, the long-short equal-weighted portfolios produce a mean monthly return (alpha) amounting to 1.19 (1.04) percent in an equal-weighted portfolio. Any of the proxies work out significantly as a negative predictor in the large firm's dataset.

Table 2. Strategies in large firms

\begin{tabular}{|c|c|c|c|c|c|c|c|c|}
\hline & \multicolumn{4}{|c|}{ Equal-weighted portfolios } & \multicolumn{4}{|c|}{ Value-weighted portfolios } \\
\hline & Low & Medium & High & High-Low & Low & Medium & High & High-Low \\
\hline \multicolumn{9}{|c|}{ Panel A: Portfolios from sorts on the earnings-to-price ratio } \\
\hline \multirow[t]{2}{*}{$\mathrm{R}$} & 0.80 & $1.77^{\star \star}$ & $1.37^{\star \star}$ & 0.56 & 0.99 & $1.59^{\star \star}$ & $1.33^{\star \star}$ & 0.35 \\
\hline & $(1.01)$ & (2.23) & (2.18) & (0.93) & $(1.30)$ & $(2.06)$ & (2.08) & $(0.54)$ \\
\hline Vol & 10.95 & 10.24 & 9.22 & 8.20 & 10.33 & 9.92 & 9.59 & 8.40 \\
\hline SR & 0.25 & 0.60 & 0.51 & 0.24 & 0.33 & 0.56 & 0.48 & 0.14 \\
\hline \multirow[t]{3}{*}{$\alpha$} & -0.32 & $0.74^{*}$ & 0.34 & 0.66 & -0.10 & 0.63 & 0.29 & 0.39 \\
\hline & $(-0.88)$ & $(1.81)$ & (1.14) & (1.22) & $(-0.31)$ & (1.64) & $(0.95)$ & $(0.78)$ \\
\hline & \multicolumn{8}{|c|}{ Panel B: Portfolios from sorts on the book-to-market ratio } \\
\hline \multirow[t]{2}{*}{$\mathrm{R}$} & 0.47 & $1.43^{* *}$ & $1.66^{\star *}$ & $1.19^{* *}$ & 0.58 & $1.49^{* *}$ & $1.51^{* *}$ & $0.93^{*}$ \\
\hline & $(0.73)$ & (2.08) & (2.21) & (2.09) & (0.92) & (2.18) & (2.02) & (1.69) \\
\hline Vol & 9.45 & 9.48 & 10.48 & 8.09 & 8.85 & 9.51 & 10.77 & 8.44 \\
\hline SR & 0.17 & 0.52 & 0.55 & 0.51 & 0.23 & 0.54 & 0.49 & 0.38 \\
\hline \multirow[t]{3}{*}{$\alpha$} & $-0.52^{\star * *}$ & 0.46 & $0.51^{* *}$ & $1.04^{\star * \star}$ & -0.35 & $0.54^{\star *}$ & 0.35 & 0.69 \\
\hline & $(-3.75)$ & (1.53) & (2.45) & (3.71) & $(-1.23)$ & (2.11) & (1.35) & (1.46) \\
\hline & \multicolumn{8}{|c|}{ Panel C: Portfolios from sorts on the dividend yield } \\
\hline \multirow[t]{2}{*}{$\mathrm{R}$} & 0.86 & $1.35^{\star *}$ & $1.52^{\star \star}$ & 0.65 & 0.67 & $1.37^{* *}$ & $1.30^{* *}$ & 0.63 \\
\hline & $(1.28)$ & (2.09) & (2.39) & $(1.02)$ & $(1.05)$ & $(2.12)$ & (2.12) & $(0.88)$ \\
\hline Vol & 10.25 & 9.06 & 9.25 & 7.92 & 9.62 & 9.24 & 9.22 & 8.53 \\
\hline SR & 0.29 & 0.52 & 0.57 & 0.28 & 0.24 & 0.51 & 0.49 & 0.26 \\
\hline \multirow[t]{3}{*}{$\alpha$} & -0.29 & 0.28 & 0.40 & 0.69 & -0.41 & 0.30 & 0.21 & 0.62 \\
\hline & $(-1.01)$ & $(0.88)$ & (1.28) & $(1.36)$ & $(-1.22)$ & $(0.92)$ & (0.83) & $(1.20)$ \\
\hline & \multicolumn{8}{|c|}{ Panel D: Portfolios from sorts on the EBITDA-to-EV ratio } \\
\hline \multirow[t]{2}{*}{$\mathrm{R}$} & 0.91 & $1.35^{\star}$ & $1.31^{*}$ & 0.40 & 0.89 & $1.36^{*}$ & 1.24 & 0.35 \\
\hline & (0.95) & $(1.76)$ & (1.74) & (0.64) & (1.07) & $(1.80)$ & $(1.60)$ & (0.57) \\
\hline Vol & 11.69 & 10.26 & 10.78 & 10.33 & 10.88 & 10.10 & 11.16 & 11.39 \\
\hline SR & 0.27 & 0.46 & 0.42 & 0.13 & 0.28 & 0.47 & 0.38 & 0.11 \\
\hline \multirow[t]{2}{*}{$\alpha$} & -0.27 & 0.30 & 0.21 & 0.48 & -0.18 & 0.34 & 0.15 & 0.34 \\
\hline & $(-1.09)$ & $(0.90)$ & $(0.46)$ & (1.14) & $(-0.61)$ & (1.13) & $(0.28)$ & $(0.41)$ \\
\hline
\end{tabular}

Note. The table presents the performance of equal- and value-weighted tercile portfolios from sorts on the earnings-to-price ratio (Panel $A$ ), book-to-market ratio (Panel B), dividend yield (Panel C), EBITDA-to-EV ratio (Panel D). High (Low) represents the portfolio of stocks with the $1 / 3$ highest (lowest) values of predictive variables representing firm value, Medium represents the portfolio of stocks with predictors values between groups of $1 / 3$ highest and 1/3 lowest. High-Low is the zeroinvestment portfolio going long (short) the High (Low) tercile. $R$ is the mean monthly return, Vol represents the standard deviation, $S R$ is annualized Sharpe ratio and the symbol $\alpha$ represent the average monthly abnormal return intercepted from the CAPM model. Average returns, volatilities, alphas are expressed in percentage terms. The numbers in parentheses are Newey-West (1987) adjusted $t$-statistics for the means of returns and alphas, respectively. The asterisks *, ${ }^{* *}$, and ***indicate statistical significance at the $10 \%, 5 \%$, and $1 \%$ levels, respectively. 
In the case of long-only portfolios, the EP ratio produces a mean raw return of 1.37 (1.33) percent for the equalweighted (value-weighted) portfolio with no significant alphas. The equal-weighted (value-weighted) dividend yield portfolio demonstrates the mean raw return of 1.52 (1.30) percent with no significant alphas. Only on the equal-weighted portfolio the based on the EBITDA-to-EV ratio has statistically significant mean profits of 1.31 percent per month and non-significant alphas amounting to 0.21 percent. In Figure 3 we show cumulative returns for all analyzed proxies for large-firms strategy:

Figure 3. Cumulative returns for large firms strategy.

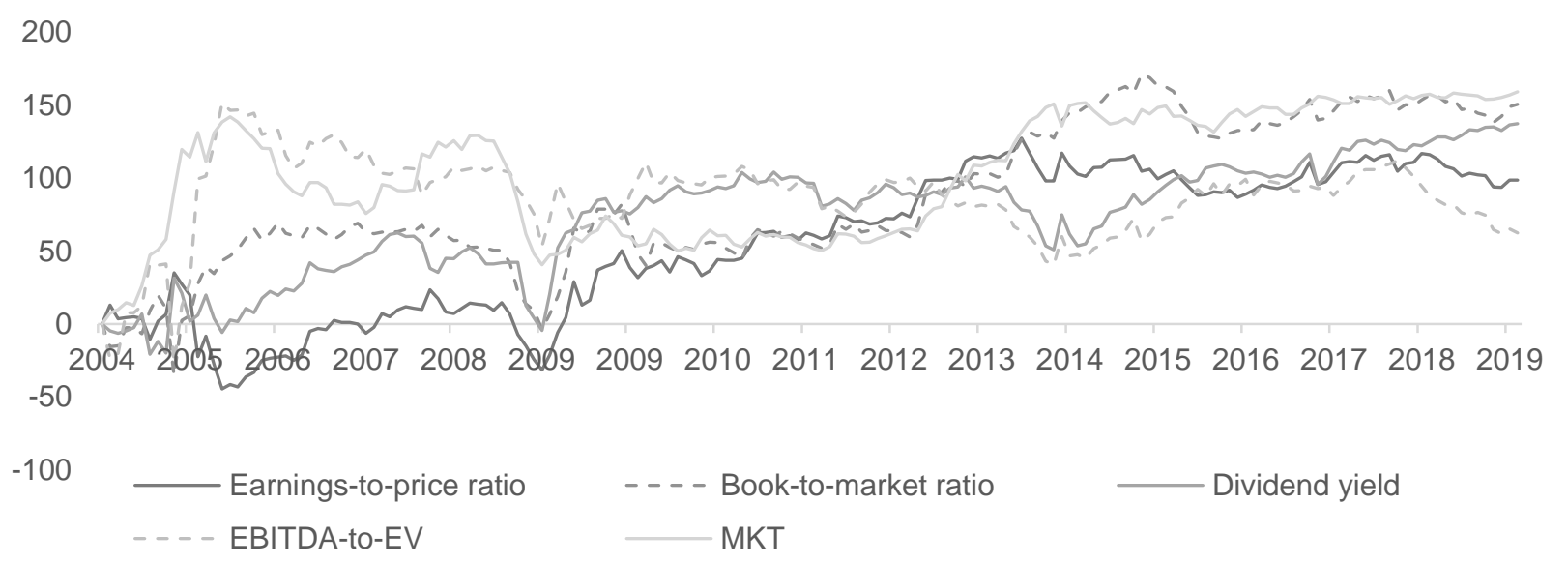

Note: The Figure presents the cumulative returns for each of the analyzed strategies and market capitalization of analyzed firms. Source: Own study.

\section{CONCLUSIONS}

The study analyses the effectiveness of the value investment strategy in the UAE stock markets. In our research, we use all listed companies in the UAE stock markets in the period from January 2004 through to March 2019. The dataset consists of 124 firms in total.

We perform portfolio sorts based on company's value proxies. We find that this strategy is effective with robust raw returns and alphas. Overall, the value investing strategy performs very well when implemented using equalweighted portfolios in a diversified and large sample of companies. For value-weighted portfolios and large companies, the phenomenon is markedly weaker.

\section{FUNDING}

This paper is a part of the project No. 2016/23/B/HS4/00731 of the National Science Centre of Poland.

\section{REFERNCES}

Al-Hajieh, H., Redhead, K. \& Rodgers, T. (2011), Investor sentiment and calendar anomaly effects: a case study of the impact of Ramadan on Islamic Middle Eastern markets. Research in International Business and Finance, 25(3), 345356.

Al-Khazali, O. M. (2008) The impact of thin trading on day-of-the-week effect: Evidence from the United Arab Emirates. Review of Accounting and Finance, 7(3), 270-284. https://doi.org/10.1108/14757700810898258

Al-Tamimi, H. A. H., Alwan, A. A., \& Abdel Rahman, A. A. (2011). Factors affecting stock prices in the UAE financial markets. Journal of Transnational Management, 16(1), 3-19. https://doi.org/10.1080/15475778.2011.549441

Alshebli, A. R. A. S. (2019). Fair disclosure of inside information by listed companies: A comparative study between the UK and Kuwait. Journal of Research in Emerging Markets, 1(1), 13-23. https://doi.org/10.30585/jrems.v1i1.317

Asness, C. S., Moskowitz, T. J., \& Pedersen, L. H. (2013). Value and momentum everywhere. Journal of Finance, 68 (3), 929-985.

Basu, S. (1975). The Information content of price-earnings ratios. Financial Management, 4 (2), $53-64$.

Basu, S. (1977). Investment performance of common stocks in relation to their price-earnings ratios: A test of the efficient market hypothesis. Journal of Finance, 32, 663-682.

Basu, S. (1983). The relationship between earnings yield, market value and return for NYSE common stocks: Further evidence. Journal of Financial Economics, 12, 129-156.

Bedier, R. E., \& H. Abdel-Azim, M. H. (2019). Information processing effects of accounting consistency: Evidence from Egypt. Journal of Research in Emerging Markets, 1(2), 1-15. https://doi.org/10.30585/jrems.v1i2.322 
Brouwer, I., van der Put, J., \& Veld, C. (1996).Contrarian investment strategies in the European context. Working paper. Retrieved October 9, 2015, from SRN: http://ssrn.com/abstract=41003 orhttp://dx.doi.org/10.2139/ssrn.41003

Campbell, J. Y., \& Yogo, M. (2006). Efficient tests of stock return predictability. Journal of Financial Economics, 81 (1), 27 60.

Chan, L. K. C., Hamao, Y., \& Lakonishok, J. (1991). Fundamentals and stock returns in Japan. Journal of Finance, 46, 1739-1764.

Chiang, C.T. \& Zheng, D. (2010), An empirical analysis of herd behavior in global stock markets. Journal of Banking and Finance, Vol. 34 No. 8, pp. 1911-1921.

Da Silva, A. L. C. (2001). Empirical tests of the Dogs of the Dow strategy in Latin American stock markets. International Review of Financial Analysis, 10 (2), 187-199.

Damodaran, A. (2012). Investment valuation: Tools and techniques for determining the value of any asset(3 ed.). New York: Wiley.

de Groot, W., Pang, J., \& Swinkels, L. A. P. (2012). The cross-section of stock returns in frontier emerging markets. Journal of Empirical Finance, 19 (5), 796-818.

Fama, E. F., \& French, K. R. (1992). The cross-section of expected returns. Journal of Finance, 47, 427-466.

Fama, E. F., \& French, K. R. (1988). Dividend yields and expected stock returns. Journal of Financial Economics, 22, 3-25.

Fama, E. F., \& French, K. R. (1998). Value versus growth: The international evidence. Journal of Finance, 53 (6), 19751999

Goetzmann, W. N., \& Jorion, P. (1995). A longer look at dividend yields. Journal of Business, 68, 483-508.

Graham, B. (2006). The intelligent investor: The definitive book on value investing. A book of practical counsel. New York: Harper Business.

Graham, B. (2008). Security Analysis (6 ed.). New York: McGraw-Hill Education.

Gray, W. R., \& Vogel, J. (2012). Analyzing valuation measures: A performance horse race over the past 40 years. Journal of Portfolio Management, 39 (1), 112-121.

Kouzez, M., \& Lecointre-Erickson, D. (2019). Does crisis affect credit risk in developing countries? The Case of the Jordanian Market. Journal of Research in Emerging Markets, 1 (1), 24-37. https://doi.org/10.30585/jrems.v1i1.327

Loughran, T., \& Wellman, J. W. (2011). New evidence on the relation between the enterprise multiple and average stock returns. Journal of Financial and Quantitative Analysis, 46, 1629-1650.

Maghyereh, A \& Awartani, B. (2012). Return and volatility spillovers between Dubai financial market and Abu Dhabi Stock Exchange in the UAE. Applied Financial Economics. 22. 837-848. https://doi.org/10.1080/09603107.2011.628292

Medhioub, I. \& Chaffai, M. (2018). Islamic finance and herding behavior: an application to Gulf Islamic stock markets. Review of Behavioral Finance, 10 (2), 192-206. https://doi.org/10.1108/RBF-02-2017-0014

Moustafa, M. (2004). Testing the weak-form efficiency of the United Arab Emirates stock market. International Journal of Business, 9, 309-325.

Newey, W.K. \& West K.D. (1987). A Simple, Positive Semi-Definite, Heteroskedasticity and Autocorrelation Covariance Matrix, Econometrica 55 (3), 703-708

Nicholson, F. (1960). Equilibrium in capital asset market. Econometrica, 34, 768-783.

Rosenberg, B., Reid, K., \& Lanstein, R. (1985). Persuasive evidence of market inefficiency. Journal of Portfolio Management, 11, 9-17.

Sharpe, W. F. (1964). Capital asset prices: A theory of market equilibrium under conditions of risk. Journal of Finance, 19(3), 425-442.

Sharpe, W. F. (1966). Mutual fund performance (pp. 119-138). January: Journal of Business.

Soomro, N., \& Haroon, M. A. (2015). Comparison of Dogs of the Dow Strategy. Universal Journal of Management, 3 (3), 127-130.

Zaremba, A., \& Konieczka, P. (2015). Do quantitative country selection strategies really work? Journal of Investment Strategies, 5 (2), 1-33. https://doi.org/10.21314/jois.2016.068

Zaremba, A., \& Szyszka, A. (2016). Is there momentum in equity anomalies? Evidence from the Polish emerging market. Research in International Business and Finance, 38, 546-564. https://doi.org/10.1016/j.ribaf.2016.07.004

Zaremba, A., Czapkiewicz, A., Szczygielski, J. J., \& Kaganov, V. (2019). An application of factor pricing models to the Polish stock market. Emerging Markets Finance and Trade, 55 (9), $2039-2056$ https://doi.org/10.1080/1540496X.2018.1517042 